(2) Open Access Full Text Article

\title{
Atorvastatin, a double weapon in osteoporosis treatment: an experimental and clinical study
}

This article was published in the following Dove Press journal:

Drug Design, Development and Therapy

2 May 2017

Number of times this article has been viewed

\author{
Naglaa El-Nabarawi' \\ Mohamed El-Wakd ${ }^{2}$ \\ Mostafa Salem ${ }^{3}$ \\ 'Faculty of Medicine, National \\ Egyptian Center of Environmental \\ and Toxicological Research, \\ ${ }^{2}$ Rheumatology and Rehabilitation \\ Department, ${ }^{3}$ Clinical Pathology \\ Department, Faculty of Medicine, \\ Cairo University, Cairo, Egypt
}

Objective: The aim of this study was to evaluate the effect of atorvastatin on the bone formation and resorption markers in ovariectomized rats (experimental study), and to study its effect on the bone mineral density (BMD) in postmenopausal osteoporotic women (clinical study).

Materials and methods: The study involved experimental and clinical aspects. In the experimental aspect, 42 female Wistar rats were divided into five groups: Group I ( $\mathrm{n}=6$; sham-operated), Group II ( $\mathrm{n}=6 ; 1 \mathrm{~mL}$ of carboxymethyl cellulose [CMC] was administered orally), Group III ( $\mathrm{n}=6$; $20 \mathrm{mg} / \mathrm{kg}$ orally of atorvastatin was administered), Group IV ( $\mathrm{n}=12$; untreated ovariectomized [OVX] rats and served as a model of osteoporosis [OP]) and Group V ( $\mathrm{n}=12 ; 20 \mathrm{mg} / \mathrm{kg}$ orally of atorvastatin was administered to ovariectomized rats). After 4 weeks, serum acid phosphatase, alkaline phosphatase, osteocalcin, total calcium and inorganic phosphorus were assessed. Then, $3 \mu \mathrm{m}$ thickness lumbar and femur sections were examined using a light microscope to assess cortical thickness, trabecular area, numbers of osteoblasts and osteoclasts. In the clinical aspect, 85 post-menopausal osteoporotic females with recently detected hyperlipidemia participated in the study. Atorvastatin $40 \mathrm{mg}$ /day, calcium carbonate $500 \mathrm{mg}$ /day and vitamin D 800 international units were given to all patients for a period of 18 months. BMD was measured at the start and at the end of the study by dual-energy X-ray absorptiometry (DEXA).

Results: In the experiment aspect, the biomarkers of bone remodeling were notably elevated in the OVX group. Administration of atorvastatin produced a significant decrease in the level of these bone metabolic markers. Atorvastatin significantly ameliorates osteoporotic changes induced by ovariectomy. In the clinical aspect, after 18 months the DEXA showed improvement in the T-score for the three measured zones; however, these changes were statistically significant only in the femoral neck area.

Conclusion: Atorvastatin was able to decrease the rate of bone metabolism and increase osteogenic activity. It has dual mode of action; both anabolic and antiresorptive effect on bone. This lipophilic statin member may act as a double weapon drug.

Keywords: atorvastatin, statin, osteoporosis, BMD, bone formation

\section{Introduction}

Osteoporosis (OP) is defined as a systemic skeletal disorder characterized by low bone mass and micro-architectural deterioration of bone tissue with a consequent increase in bone fragility and susceptibility to fracture risk. It is a serious global health problem associated with high morbidity and mortality, as well as drastic economic burden. ${ }^{1}$ Several drugs with different mechanisms of action have been used for OP with the aim of preventing fracture through inhibition of bone resorption or stimulation of bone formation. All currently available approved therapies for OP work by inhibiting the normal breakdown and resorption of bone. Such antiresorptive therapies include calcitonin, estrogen replacement therapy, selective estrogen receptor
Correspondence: Naglaa El-Nabaraw National Egyptian Center of Environmental and Toxicological Research (NECTER), Faculty of Medicine, Cairo University, Cairo, Egypt Emailn.a.nabarawy@gmail.com 
modulators (Raloxifene), and bisphosphonates (alendronate sodium and risedronate sodium). These therapies are unable to increase bone mass but modestly reduce the risk of new fractures. ${ }^{2}$ Bisphosphonates inhibit farensyl pyrophosphate synthetase, which is responsible for the transformation of geranyl pyrophosphate into farensyl pyrophosphate, and then to geranylgeranyl pyrophosphate which is responsible for osteoclast activation and subsequent bone resorption, through formation of its ruffled borders needed to seal off the bone surface for proper release of proteolytic enzymes and acid that dissolves the underlying bone. However, the safety of oral bisphosphonates has been questioned due to adverse events from the upper gastrointestinal tract, acute phase response, hypocalcaemia, secondary hyperparathyroidism, musculoskeletal pain and osteonecrosis of the jaw. 3,4

Statins are structural analogs of 3-hydroxy-3-methyl glutaryl-coenzyme A and competitively inhibit the HMGCoA reductase enzyme, which is responsible for the first committed step in sterol biosynthesis. Statins that are approved for use include lovastatin, pravastatin, simvastatin, fluvastatin, cerivastatin, atorvastatin and rosuvastatin. They effectively lower the cholesterol levels, thereby reducing the risk of ischemic heart disease, and stroke. They can also modify endothelial function, control inflammatory response, promote plaque stability, inhibit thrombus formation, reduce platelet aggregation, increase collagen and smooth muscle cells, and maintain a balance between prothrombotic and fibrinolytic mechanisms. ${ }^{5}$ These are used in the treatment of hyperlipidemia and act on the same pathway of bisphosphonates but on an earlier step. With respect to the ability of statins to inhibit the HMG-CoA reductase, a key enzyme in the pathways of cholesterol synthesis as well as in the process of activation of osteoclasts, many studies had suggested that statins may have additional important therapeutic effects known as pleiotropic or cholesterol-independent effects via other molecular pathways..$^{5-7}$ Both hydrophilic and lipophilic statins inhibit HMG-CoA reductase; however, it was proven that only the lipophilic statins predominantly induce bone morphogenetic protein-2 (BMP-2) expression, which promotes differentiation of mesenchymal stem cells into differentiated osteoblasts and bone formation. ${ }^{7,8}$ Several in vitro and in vivo animal studies had proven its dual effect with bone formation, as well as antiresorptive effects. ${ }^{9-11}$

The aim of this study was to investigate the effect of atorvastatin (lipophilic statins) on the bone formation and resorption markers in ovariectomized rats (experimental study) and its effect on the bone mineral density (BMD) in postmenopausal osteoporotic women (clinical study).

\section{Materials and methods Experimental study}

\section{Animals}

Animals were housed and cared for in the Animal Resource Center, and were allowed free access to standard dry pellet diet and water ad libitum. All procedures were in accordance with the National Institute of Health guidelines for the care and use of laboratory animals. The study was approved by the Research Ethics Committee of the Faculty of Medicine Cairo University (472-01-2013).

\section{Experimental protocol}

Forty-two adult female Wistar rats were included in the current study for 4 weeks. Their weights ranged from 200 to 250 grams, and they were caged in fully ventilated room and exposed to natural daily (12:12 h light-dark cycle). These animals were grouped in polyacrylic cages and maintained under standard laboratory conditions (temperature $25^{\circ} \mathrm{C} \pm 2{ }^{\circ} \mathrm{C}$ and $50 \% \pm 5 \%$ relative humidity). They were allowed free access to standard dry pellet diet and water ad libitum. They were acclimated for 1 week before randomly allocated to groups. The rats were anesthetized by sodium pentobarbital (40 mg/kg, i.p.) ${ }^{12}$ before surgical operation.

\section{Animals and experimental protocol}

The animals were classified into five groups: Group I: (six rats) sham-operated group (control rats group) included nonovariectomized untreated rats. Group II included six normal rats that received $1 \mathrm{~mL}$ of carboxymethyl cellulose (CMC) orally daily. Group III included six normal rats who received atorvastatin. Group IV included 12 rats that were ovariectomized (OVX) and served as a model of OP. Group V included 12 ovariectomized rats receiving atorvastatin that was started on the fifth postoperative day and continued for 4 weeks.

Following the method outlined by Lasota and DanowskaKlonowska, ${ }^{13}$ the ovary was resected bilaterally through longitudinal dorsal midline skin incision. After skin incision, a second incision was made about halfway down the side of the abdominal wall into the dorsolateral musculature to enter the abdominal cavity in the region of a peri-ovarian fat pad. The ovary was exteriorized by grasping peri-ovarian fat with tissue forceps, and the pedicle was ligated and excised between the uterine horn and the fallopian tube. The uterine horn was returned to the abdominal cavity. The process was repeated for the other side. Both incisions on the abdominal cavity musculature were closed with suture. Sham-operated animals underwent the same procedure as the ovariectomized rats but without resection of the ovaries. CMC was used as 
a solvent for atorvastatin. It was dissolved in distilled water at a concentration of $0.5 \mathrm{mg} / 100 \mathrm{~mL}$ of distilled water. Atorvastatin was used at a dose of $20 \mathrm{mg} / \mathrm{kg} /$ day by oral gavage for 4 weeks. ${ }^{14}$ After 4 weeks, venous blood samples were collected from the retro-orbital plexus of all groups in capillary glass tubes and were incubated at $37^{\circ} \mathrm{C}$ until blood clotted, and then were centrifuged to separate serum. Serum samples were analyzed for measurement of two bone formation markers: total alkaline phosphatase (ALK-P) and osteocalcin $(\mathrm{OCN})$; and the bone resorption marker acid phosphatase (ACP), as well as measurement of total calcium and inorganic phosphorus.

\section{Histopathological evaluation}

After collection of blood samples, four rats from each group were sacrificed. The lumbar vertebrae and the femur sections were removed and were fixed in 10\% natural buffered formalin and embedded in paraffin for a light microscope study. Sections with $3 \mu \mathrm{m}$ thickness were prepared and stained with hematoxylin and eosin (H\&E). The cortical thickness and trabecular area in femur and vertebra were examined, as well as the osteoblast, osteoclast and new blood vessels formation.

\section{Clinical study}

Eighty-five postmenopausal females participated from the Rheumatology and Rehabilitation outpatient clinic, Cairo University hospitals, during the period from January 2013 till November 2014. All women who were included in the current study provided a written informed consent prior to their inclusion. This study was approved by the research ethics committee of the Faculty of Medicine - Cairo University (472-01-2013).

Patients' selection depended upon the following criteria: 1) They had OP confirmed by dual-energy X-ray absorptiometry (DEXA). ${ }^{15}$ 2) They were newly diagnosed with hyperlipidemia at the time of the study. 3) These patients had esophageal and gastric diseases that interfered with bisphosphonates treatment. 4) Patients who were taking or had a history of either antiresorptive, bone-forming or lipidlowering drugs or had any disease responsible for secondary OP were excluded from the current study. Atorvastatin $40 \mathrm{mg} /$ day, calcium carbonate $500 \mathrm{mg} /$ day and vitamin D 800 international units were given to all patients for a period of 18 months.

The following investigations were done to all patients:

Estimation of the serum lipid profile at the start of the study to confirm hyperlipidemia. All our patients had increased serum total cholesterol level $>240 \mathrm{mg} / \mathrm{dL}$ (normal $<200 \mathrm{mg} / \mathrm{dL}$ ), elevated level of low density lipoprotein cholesterol $>160 \mathrm{mg} / \mathrm{dL}$ (normal $<129 \mathrm{mg} / \mathrm{dL}$ ), lower level of high density lipoprotein cholesterol $<40 \mathrm{mg} / \mathrm{dL}$ (nor$\mathrm{mal}>60 \mathrm{mg} / \mathrm{dL}$ ) and increased triglyceride level $>200 \mathrm{mg} / \mathrm{dL}$ (normal $<150 \mathrm{mg} / \mathrm{dL}$ ). ${ }^{16}$ DEXA, using the Lunar Prodigy equipment (GE Lunar Corporation, Madison, WI, USA), was used to measure BMD according to diagnostic categories that had been proposed by World Health Organization ${ }^{15}$ and modified by the International Osteoporosis Foundation. ${ }^{17}$ Patients included in the study had BMD 2.5 standard deviation (SD) or below the young adult female mean (T-score $<-2.5$ ).

\section{Statistical analysis}

Data were collected, revised and entered into a computer. These were analyzed by SPSS statistical package, version 19 (IBM Corporation, Armonk, NY, USA). Excel computer program was used to tabulate the results and represent it graphically. For the quantitative variables which are normally distributed, a paired $t$-test was used to declare the significant difference at $P<0$.05. The significant difference between groups was shown using one-way analysis of variance (ANOVA) test at $P<0.05$, followed by Duncan's multiple comparison test at $P<0.05$ to declare the significance between each of two groups. ${ }^{18}$

\section{Results Experimental study}

The mean serum ACP in the two groups of rats that received atorvastatin only and ovariectomized rats (model group) was significantly elevated to $29.43 \pm 2.00 \mu \mathrm{g} / \mathrm{L}$ and $61.95 \pm 4.97 \mu \mathrm{g} / \mathrm{L}$, respectively, compared to the control group $23.20 \pm 1.76 \mu \mathrm{g} / \mathrm{L}$. In the fifth group, ovariectomized rats that received atorvastatin showed a significant reduction of serum ACP to $30.27 \pm 0.63 \mu \mathrm{g} / \mathrm{L}$ compared to osteoporotic rats group $\mathrm{IV}, 61.95 \pm 4.97 \mu \mathrm{g} / \mathrm{L}$, as shown in Table 1 .

Rats that received atorvastatin (group III) and ovariectomized rats (group IV) showed a statistically significant increased level of serum ALK-P compared to control groups $(193.83 \pm 41.48 \mu \mathrm{g} / \mathrm{L}$ and $125.87 \pm 3.39 \mu \mathrm{g} / \mathrm{L}$ versus $121.63 \pm 3.56$ $\mu \mathrm{g} / \mathrm{L})$. Also, ovariectomized rats that received atorvastatin (group V) was associated with a significant decrease of serum ALK-P in comparison to the OP group $(120.23 \pm 4.66 \mu \mathrm{g} / \mathrm{L}$ versus $125.87 \pm 3.39 \mu \mathrm{g} / \mathrm{L}$ ), as shown in Table 1 .

The mean serum OCN level was significantly increased in rats that received atorvastatin (group III) and ovariectomized rats (group IV) in comparison with sham (group I), $5.18 \pm 0.23 \mathrm{ng} / \mathrm{L}$ and $6.47 \pm 0.15 \mathrm{ng} / \mathrm{L}$ versus $3.30 \pm 0.25 \mathrm{ng} / \mathrm{L}$, respectively. 
Table I The mean serum level of bone resorption and formation markers among the five groups

\begin{tabular}{llllll}
\hline Group & $\begin{array}{l}\text { ACP } \\
(\mu \mathrm{g} / \mathbf{L})\end{array}$ & $\begin{array}{l}\text { ALK-P } \\
(\mu \mathrm{g} / \mathbf{L})\end{array}$ & $\begin{array}{l}\text { OCN } \\
(\mathbf{n g} / \mathbf{L})\end{array}$ & $\begin{array}{l}\text { Total calcium } \\
(\mathbf{m g} / \mathbf{L})\end{array}$ & $\begin{array}{l}\text { Inorganic phosphate } \\
(\mathbf{m g} / \mathbf{L})\end{array}$ \\
\hline Group I, SHAM rats & $23.20 \pm 1.76^{\mathrm{a}}$ & $121.63 \pm 3.56^{\mathrm{b}}$ & $3.30 \pm 0.25^{\mathrm{a}}$ & $13.30 \pm 0.62^{\mathrm{b}}$ & $10.17 \pm 0.43^{\mathrm{c}}$ \\
Group II, CMC & $40.47 \pm 5.04^{\mathrm{c}}$ & $80.88 \pm 5.30^{\mathrm{a}}$ & $3.55 \pm 0.3 \mathrm{I}^{\mathrm{a}}$ & $13.03 \pm 0.59^{\mathrm{b}}$ & $8.10 \pm 1.74^{\mathrm{b}}$ \\
Group III, atorvastatin dissolved in CMC & $29.43 \pm 2.00^{\mathrm{b}}$ & $193.83 \pm 41.48^{\mathrm{d}}$ & $5.18 \pm 0.23^{\mathrm{c}}$ & $13.47 \pm 1.06^{\mathrm{b}}$ & $7.27 \pm 0.70^{\mathrm{a}}$ \\
Group IV, OVX (model of OP) & $61.95 \pm 4.97^{\mathrm{d}}$ & $125.87 \pm 3.39^{\mathrm{c}}$ & $6.47 \pm 0.15^{\mathrm{d}}$ & $10.43 \pm 0.60^{\mathrm{a}}$ & $7.45 \pm 0.79^{\mathrm{a}}$ \\
Group V, OVX + atorvastatin & $30.27 \pm 0.63^{\mathrm{b}}$ & $120.23 \pm 4.66^{\mathrm{b}}$ & $4.93 \pm 0.22^{\mathrm{b}}$ & $12.57 \pm 0.97^{\mathrm{b}}$ & $10.70 \pm 1.26^{\mathrm{c}}$ \\
F-ratio & 120.842 & 30.068 & 58.265 & 17.982 & 12.848 \\
P-value & $<0.00 \mathrm{C}$ & $<0.001$ & $<0.001$ & $<0.001$ & $<0.00 \mathrm{I}$ \\
\hline
\end{tabular}

Notes: There is a significant difference by using one way ANOVA at $P<0.05$. The same letter means that there is no significant difference between the two groups by using Duncan's multiple comparison test at $P<0.05$. The different letters mean that there is a significant difference between the two groups by using Duncan's multiple comparison test at $P<0.05$.

Abbreviations: ACP, acid phosphatase; ALK-P, alkaline phosphatase; ANOVA, analysis of variance; OCN, osteocalcin; CMC, carboxy methyl cellulose; OVX, ovariectomized; OP, osteoporosis.

Also, administration of atorvastatin to the ovariectomized rats (group V) was associated with a significant decrease of OCN level in comparison with the OP model $(4.93 \pm 0.22 \mathrm{ng} / \mathrm{L}$ versus $6.47 \pm 0.15 \mathrm{ng} / \mathrm{L}$ ), as shown in Table 1 .

The mean calcium level in the osteoporotic group (group IV) was significantly decreased to $10.43 \pm 0.60 \mathrm{mg} / \mathrm{L}$ compared to the control group (group I), $13.30 \pm 0.62 \mathrm{mg} / \mathrm{L}$. Ovariectomized rats that received atorvastatin (group V) were associated with a significant increase of serum calcium level compared to the model group of OP (group IV; $12.57 \pm$ $0.97 \mathrm{mg} / \mathrm{L}$ versus $10.43 \pm 0.60 \mathrm{mg} / \mathrm{L}$ ), as shown in Table 1 .

Atorvastatin administration in normal rats significantly reduced the level of serum inorganic phosphate compared to the normal group $(7.27 \pm 0.70 \mathrm{mg} / \mathrm{L}$ versus $10.17 \pm 0.43 \mathrm{mg} / \mathrm{L})$. In the OP model group, the mean serum inorganic phosphate level was significantly decreased to $7.45 \pm 0.79 \mathrm{mg} / \mathrm{L}$ compared to the normal group. In group $\mathrm{V}$, the mean serum level of inorganic phosphate was raised significantly to $10.70 \pm 1.26 \mathrm{mg} / \mathrm{L}$ compared to the OP model group, as shown in Table 1.

The histopathological examination of rat bones showed numerous trabeculae, osteoblast cells and blood vessels in the atorvastatin group (Figure 1). While those ovariectomized rats, the OP model, showed widely spaced thin bone trabeculae with fatty bone marrow filling the spaces between the trabeculae.

\section{Clinical study}

Of the 85 patients, only 70 completed the study throughout the follow-up duration of 18 months ( 2 died, 7 noncompliant to treatment and 6 lost to follow-up). The demographic data of finally included 70 patients are shown in Table 2. Mean T-scores of femoral neck, lumbar spine and distal radius measured by DEXA at the start and at the end of the study were shown in Table 3. None of them had fractured during the study period. After 18 months, the DEXA showed improvement of the T-score for the three measured zones; however, these changes were statistically significant only in the femoral neck area $(P=0.009)$.

\section{Discussion}

Ovariectomy has shown an increased risk of OP as it occurs in postmenopausal women. Moreover, the ovariectomized rat is considered the gold standard model for evaluation of
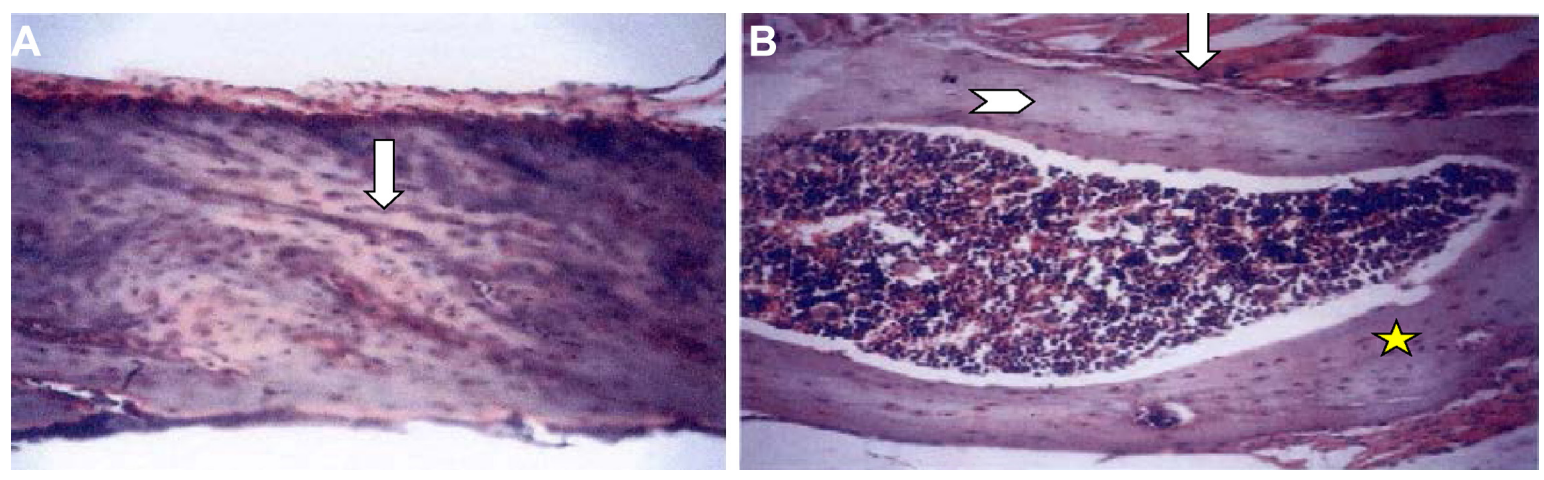

Figure I (Continued) 

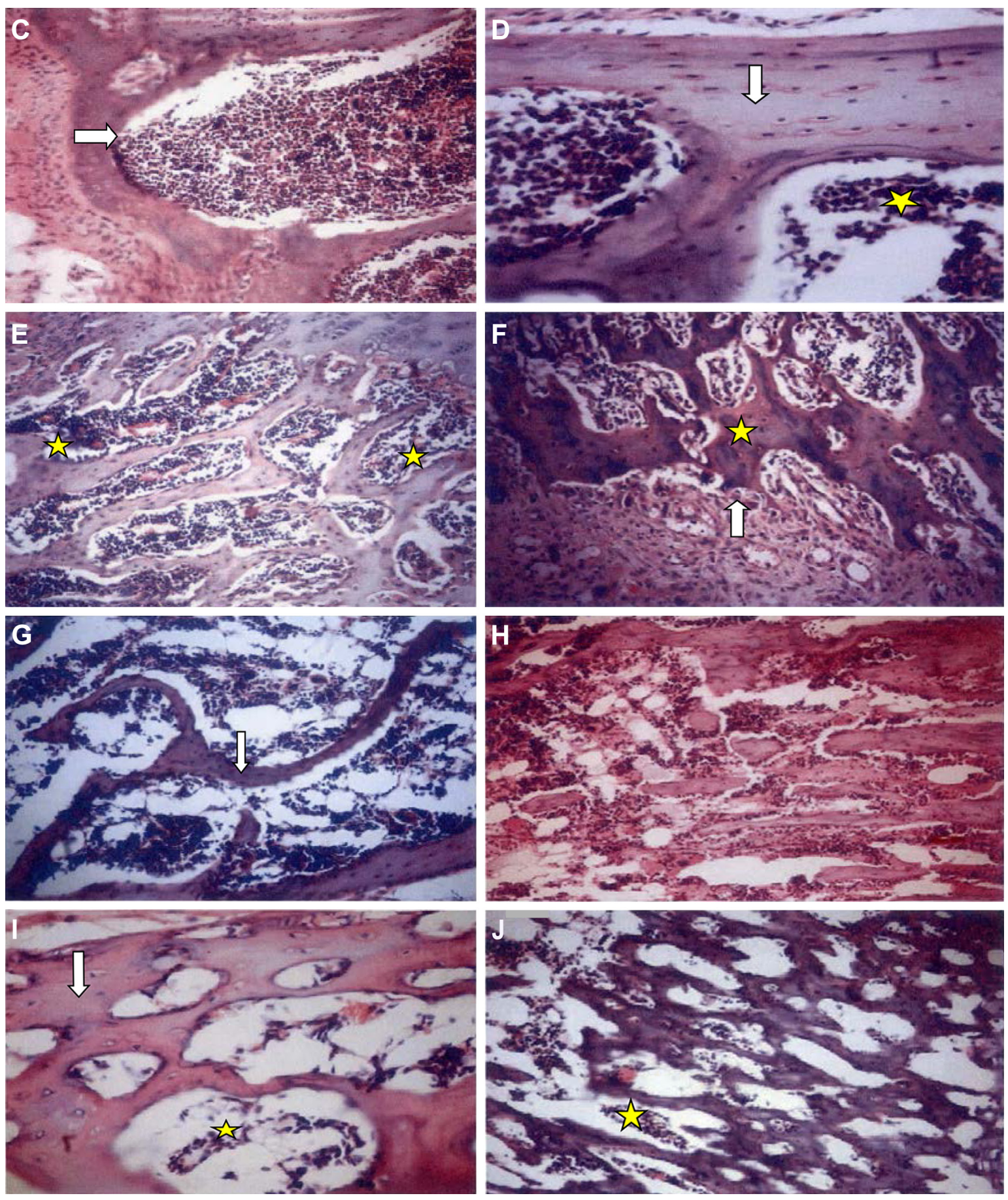

Figure I Histopathological examination of rats' bones of the five groups by light microscopy stained by H\&E. $(\times 200)$.

Notes: Sections with $3 \mu \mathrm{m}$ thickness were prepared and stained with H\&E. The cortical thickness and trabecular area in femur and vertebra were examined. Histopathological examination of rat bones showed numerous trabeculae, osteoblast cells and blood vessels in the atorvastatin group. These have been indicated by arrowheads and stars. (A) Group I: Section in a femur bone, revealed part of compact bone formed of osteons surrounded by several lamellae of bone, connected by Volkmann's canal (arrow). (B) Group I: Section in a femur bone showed part of skeletal muscle fibers attached to the outer fibrous periosteum (arrow). Note the presence of osteons surrounded by interstitial lamellae (star). The inner circumferential lamellae (arrowhead) were separating the bone from the marrow cavity. (C) Group II: Section in a femur bone revealed large open spaces of bone marrow lined by endosteum (arrow) and separated by trabeculae of bone composed of several lamellae. (D) Group II: Section in a lumbar vertebra revealed large open spaces filled with bone marrow (star) and separated by trabeculae of well-formed bone (arrow) composed of several lamellae. (E) Group III: Section in a femur bone revealed a zone of calcifying cartilage (upper right). The rest of the slide showed numerous trabeculae of bone (star) with wide spaces of bone marrow, osteogenic cells and blood vessels. (F) Group III: Section in a femur bone revealed interlacing trabeculae of intensely basophilic trabeculae of woven bone with large and round osteocytes (star). The lower part of the section showed proliferated blood vessels, osteoclasts forming shallow depressions on the bone (arrow) and part of the periosteal tissue. (G) Group IV: Section in a femur bone revealed widely spaced thin bone trabeculae (arrow) lined by flattened osteoblasts, with fatty marrow filling the spaces between the trabeculae. (H) Group IV: Section in lumbar vertebra revealed widely spaced thin bone trabeculae, surrounding scant bone marrow material. (I) Group V: Section in a lumbar vertebral bone revealed trabeculae of bone formed of lenticular-shaped osteocytes (arrow) surrounding wide spaces filled with a scant amount of bone marrow (star) (J) Group V: Section in a femur showed trabeculae of bone surrounding wide spaces filled with a scant amount of bone marrow (star).

Abbreviation: H\&E, hematoxylin and eosin. 
Table 2 Demographic data of the examined 70 postmenopausal patients

\begin{tabular}{ll}
\hline Parameter & $\begin{array}{l}\text { Patients }(\mathbf{N}=\mathbf{7 0}) \\
\text { Range (mean } \pm \mathbf{S D})\end{array}$ \\
\hline Age (years) & $60-78(67.3 \pm 5.3)$ \\
Weight $(\mathrm{kg})$ & $43-119(72 \pm 13.9)$ \\
Height $(\mathrm{m})$ & $1.49-1.79(1.55 \pm 0.05)$ \\
BMI $\left(\mathrm{kg} / \mathrm{m}^{2}\right)$ & $17-48(30 \pm 5.9)$ \\
\hline
\end{tabular}

Notes: Bisphosphonates intake was contraindicated in all these patients mainly due to upper gastrointestinal problems (esophagitis, gastritis and history of peptic ulceration in 18,32 and 20 patients, respectively).

Abbreviations: $\mathrm{Kg}$, kilogram; $\mathrm{m}$, meter; $\mathrm{BMI}$, body mass index; DEXA, dual-energy $\mathrm{X}$-ray absorptiometry.

drugs used in the prevention and treatment of OP. It has been well validated and shares many clinical similarities with estrogen deficiency induced or postmenopausal bone loss in adult humans. ${ }^{19}$ This study revealed increased serum level of ACP and ALK-P in ovariectomized rats which contributes to high bone turnover rate, being characterized by an increase in both bone resorption and formation, but bone resorption exceeds formation, leading to bone loss ${ }^{20}$ thus, indicating an increase in osteoblastic and osteoclastic activity, respectively, resulting in an overall net loss of bone.

Our results are compatible with those reported by Riggs and Melton ${ }^{21}$ who found that menopause results in elevated bone turnover, an imbalance between bone formation and bone resorption and net bone loss, and this is attributed to the cessation of ovarian function and tapering off of estrogen secretion. ${ }^{20-22}$ Also, the present work showed an increased level of serum OCN in ovariectomized rats. Some researchers reported that $\mathrm{OCN}$ is a non-collagenous matrix protein produced by osteoblasts and serum OCN correlates with the rate of bone mineralization. ${ }^{23}$

These results coincided with those of Abdallah et al, ${ }^{24}$ who showed that ovariectomy induced a rise in serum OCN level as a result of compensation of increased bone turnover.

Furthermore, Seibe ${ }^{25}$ showed that changes in serum OCN concentration represent changes in whole skeleton bone

Table $3 \mathrm{~T}$-scores of femoral neck, lumbar spine and distal radius of the examined 70 patients at the start and at the end of the 18 months study period

\begin{tabular}{lllll}
\hline T-score & Mean \pm SD & t-value & P-value \\
\hline Femoral neck & At start & $-2.52 \pm 0.92$ & 1.99 & 0.048 \\
& At end & $-2.22 \pm 0.81$ & & \\
Lumbar spine & At start & $-2.99 \pm 1.28$ & 1.85 & 0.07 \\
& At end & $-2.96 \pm 1.26$ & & \\
Distal radius & At start & $-2.98 \pm 1.79$ & 1.58 & 0.12 \\
& At end & $-2.92 \pm 1.80$ & & \\
\hline
\end{tabular}

Abbreviation: SD, standard deviation. metabolism. Moreover, serum OCN levels are most likely to either reflect newly synthesized protein or that released from the bone matrix during resorption. ${ }^{26,27}$

Also, the present work indicated that the levels of bone $\mathrm{Ca}$ and $\mathrm{P}$ in ovariectomized rats were significantly lower than those of the control group. These results are in agreement with Mattix Kramer et al ${ }^{28}$ who reported that ovariectomized rats had impaired calcium balance that could have contributed to ovariectomy-induced OP. Menopause is associated with impaired intestinal calcium absorption that could be attributed to reduced plasma 1,25 dihydroxy vitamin D levels, as well as to the resistance of the gastrointestinal system to the action of 1,25 dihydroxy vitamin D. ${ }^{29}$ Furthermore, evidence of $\mathrm{OP}$ resulting from ovariectomy causes elevation of parathyroid hormone (PTH) level. This elevation causes additional loss of BMD beyond the rapid bone loss associated with ovariectomy. ${ }^{30}$ Moreover, ovariectomy results in hyperparathyroidism, which may, in turn, cause a change in calcium levels resulting in calcium release from skeleton, thus causing bone loss. ${ }^{31}$ The histopathological findings of this study revealed that ovariectomized rats showed reduction in the thickness of trabecular bone and increased osteoclast cells around bone marrow cavity. These results were in accordance with Zhang et $\mathrm{al}^{32}$ who found that ovariectomy caused a significant $60 \%$ reduction in trabecular bone volume, compared with sham-operated and induced increment of osteoclastogenesis. Similarly, Lane et al ${ }^{33}$ noted that OP results from both the loss of trabecular bone mass and trabecular bone connectivity. They also showed that ovariectomy resulted in approximately $50 \%$ loss of trabecular bone volume compared with sham animals.

In addition, Orlić et $a l^{34}$ found that ovariectomy induced increased bone resorption, thereby, leading to bone loss in osteoporotic-ovariectomized animals.

Moreover, D'Amelio et $\mathrm{al}^{35}$ showed that estrogen deficiency stimulates osteoclast formation both by increasing the production of osteoclastogenic cytokines as tumor necrosis factor- $\alpha$ and receptor activator of nuclear factor Kappa B Ligand (RANKL) production by activated T cells and increasing the number of osteoclast precursors. Women with postmenopausal OP have a higher T-cell activity than healthy postmenopausal women, $\mathrm{T}$ cells thus contributed to the bone loss induced by estrogen deficiency in humans as they did in the mouse.

Furthermore, our results revealed improvement in OP as shown in femur and lumbar vertebrae specimens taken from atorvastatin-treated osteoporotic rats. Thickness of trabecular bone and new blood vessels formation increased in comparison 
to the osteoporotic model with additional fibrosis which mean protection from fracture. Formation of new blood vessels for nutrition of bone was observed suggesting an anabolic process. These results were in accordance with Şipos et $\mathrm{al}^{36}$ who found that simvastatin reduces the effect of ovariectomy-induced OP, indicated by reduced percentage of intertrabecular cavities. But our results are contrary with the findings of Yao et al, ${ }^{37}$ who reported that simvastatin does not prevent or restore ovariectomy-induced bone loss in 3-month-old SpragueDawley adult female rats 120 days post ovariectomy.

The relationship between the use of statins and improvement of bone quality reported in the literature is still controversial. Some animal studies have reported positive effects of statins on bone tissue, increasing bone formation and reducing the effects of $\mathrm{OP},{ }^{38}$ bone defect healing when applied to the site of injury ${ }^{39}$ and increasing bone density. ${ }^{40}$ Our results showed that administration of atorvastatin to ovariectomized rat produces amelioration in the level of bone metabolic markers.

These results are compatible with those reported by Lin et $\mathrm{al}^{41}$ who found that the pleiotropic effect of statins derived its protective effect on the bone by the dual mechanism: suppressing osteoclasts and promoting osteoblastic activities. Also, Maeda et $\mathrm{al}^{42}$ showed that statins, such as simvastatin and cerivastatin, regulate osteoblast function by increasing the expression of bone sialoprotein, OCN and type I collagen, and by suppressing gene expression of collagenases, such as matrix metallopeptidase (MMP-1) and MMP-13.

Lipophilic statins, simvastatin, atorvastatin and cerivastatin but not hydrophilic statin, pravastatin, markedly enhance the expression of vascular endothelial growth factor, a bone anabolic factor in osteoblasts. ${ }^{43}$ Only few articles discussed the use of this predominantly lipophilic drug on BMD. ${ }^{44-46}$ Uzzan et al, in meta-analysis, ${ }^{10}$ found that statins have a statistically significant positive effect on BMD. In addition, Hughes et $\mathrm{al}^{47}$ found that the statins of hydrophobic and hydrophilic nature have inhibited osteoclastic action in vitro, while some other studies have shown that lipophilic agents like simvastatin had better action. ${ }^{7,8}$

In the clinical part, we noticed an improvement in the $\mathrm{T}$-score of the three sites after 18 months of administration of atorvastatin (40 mg/day) with vitamin D and calcium supplements in postmenopausal OP. This improvement was statistically significant in the femoral neck $(P=0.048)$ and was not significant in the predominantly cancellous bone sites. This observation supports the conclusion previously drawn in the meta-analysis of more than 20 studies. Uzzan et al found that statins showed a better action on cortical bone and positive effect on BMD in various sites, and there was a modest but statically significant favorable effect of statins on BMD; however, the reason was not understood. ${ }^{10}$ Molecular biology and genetics reveal that both vascular and osteoblast biology have a common pathway RANK/RANKL/OPG. ${ }^{48,49}$ With regard to this issue, there is growing interest concerning the possible mechanism and the impact of statins on bones on either the experimental or the clinical level. In addition, the study came in accordance with Amara et al's study which showed improvement in the BMD at the hip. ${ }^{50}$ Further studies were performed in vitro to support the potential mechanism of the beneficial effect of statins on bone metabolism. The expression of genes such as BMP-2, COLLIA1, OCN (which demonstrate an anabolic effect) and depression of others like RANKL (leading to suppression of osteoclast activity), all stimulated by statins, may regulate the role of this class of drugs in bone formation. ${ }^{51}$ Bauer et $\mathrm{al}^{52}$ in meta-analysis showed the beneficial effect of statins on the reduction of hip fractures and its positive effect on BMD. In this study, no femoral neck fracture was reported among our patients during the study period. These results are in agreement with the previous studies. Therefore in the future, statins might gain a position among drugs used for the prevention and management of OP. Their anabolic and antiresorptive effects on bone make them an ideal candidate for OP treatment.

However, we need further studies with a larger number of patients and with a longer period of follow-up.

\section{Conclusion}

The biochemical and histopathological findings of the experimental part of the study in addition to BMD findings of the clinical part showed that atorvastatin not only increased the serum bone formation markers and bone formation but also reduced the bone resorption markers, denoting that it has dual mode of action: both anabolic and antiresorptive effect, on bone. This lipophilic statin member may act as a double weapon drug.

\section{Disclosure}

The authors report no conflicts of interest in this work.

\section{References}

1. World Health Organization. Assessment of osteoporosis at the primary health care level. Summary report of a WHO scientific Group. Geneva: WHO; 2007.

2. Rossini M, Adami S, Bertoldo F, et al. Guidelines for the diagnosis, prevention and management of osteoporosis. Reumatismo. 2016;68(1):1-39.

3. Abrahamsen B. Adverse effects of bisphosphonates. Calcif Tissue Int. 2010;86(6):421-435.

4. Papapetrou PD. Bisphosphonate-associated adverse events. Hormones (Athens). 2009;8(2):96-110. 
5. Moraes LA, Vaiyapuri S, Sasikumar P, et al. Antithrombotic actions of statins involve PECAM-1 signaling. Blood. 2013;122(18):3188-3196.

6. Zhou H, Xie Y, Shi Q, Huo Q, Ma T. The effect of Atorvastatin, 3 Hydroxy-3-Methylglutaryl coenzyme A Reductase inhibitor (HMG$\mathrm{CoA}$ ) on the prevention of osteoporosis in ovariectomized rabbits. J Biomater Tissue Eng. 2016;6(6):484-492.

7. Hatzigeorgiou C, Jackson JL. Hydroxymethylglutaryl-coenzyme A reductase inhibitors and osteoporosis: a meta-analysis. Osteoporos Int. 2005;16(8):990-998.

8. Jadhav SB, Jain GK. Statins and osteoporosis: new role for old drugs. $J$ Pharm Pharmacol. 2006;58(1):3-18.

9. Toh S, Hernández-Díaz S. Statins and fracture risk. A systematic review. Pharmacoepidemiol Drug Saf. 2007;16(6):627-640.

10. Uzzan B, Cohen R, Nicolas P, Cucherat M, Perret GY. Effects of statins on bone mineral density: a meta-analysis of clinical studies. Bone. 2007;40(6):1581-1587.

11. Sharif PS, Abdollahi M. A systematic review on the relation between use of statins and osteoporosis. Int J Pharmacol. 2011;7(2):180-188.

12. Gaertner DJ, Hallman TM, Hankenson FC, Batchelder MA. Anesthesia and analgesia in rodents. In: Fish RE, Danneman P, editors. Anesthesia and Analgesia in Laboratory Animals. 2nd ed. San Diego, CA: Academic Press; 2008:239-297.

13. Lasota A, Danowska-Klonowska D. Experimental osteoporosis different methods of ovariectomy in female white rats. Rocz Akad Med Bialymst. 2004;49(Suppl 1):129-131.

14. Kawane T, Terashima S, Kurahashi I, Yanagawa T, Yoshida. Atorvastatin enhances bone density in ovariectomized rats given $17 \beta$-estradiol or human parathyroid hormone (1-34). Endocrine. 2004;24(2):121-129.

15. Kanis JA, Burlet N, Cooper C, et al; European Society for Clinical and Economic Aspects of Osteoporosis and Osteoarthritis (ESCEO). European guidance for the diagnosis and management of osteoporosis in postmenopausal women. Osteoporos Int. 2008;19(4):399-428.

16. Sidhu D, Naugler C. Fasting time and Lipid levels in a community-Based population (A cross section study). Arch Intern Med. 2012;172(22): 1707-1710.

17. Kanis JA, McCloskey EV, Johansson H, Cooper C, Rizzoli R, Reginster JY; Scientific Advisory Board of the European Society for Clinical and Economic Aspects of Osteoporosis and Osteoarthritis (ESCEO) and the Committee of Scientific Advisors of the International Osteoporosis Foundation (IOF). European guidance for the diagnosis and management of osteoporosis in postmenopausal women. Osteoporosis Int. 2013;24(1):23-57.

18. Armitage P, Berry G, Matthews JNS. Statistical Methods in Medical Research. 4th ed. London: Blackwell Science Ltd; 2002.

19. Kharode YP, Sharp MC, Bodine PV. Utility of the ovariectomized rat as a model for human osteoporosis in drug discovery. Methods Mol Biol. 2008;455:111-124.

20. El Wakf AM, Hassan HA, Gharib NS. Osteoprotective effect of soybean and sesame oils in ovariectomized rats via estrogen-like mechanism. Cytotechnology. 2014;66(2):335-343.

21. Riggs BL, Melton LJ 3rd. Involutional osteoporosis. N Engl J Med. 1986;314(26):1676-1686.

22. Heshmati HM, Khosla S, Robins SP, O'Fallon WM, Melton LJ 3rd, Riggs BL. Role of low levels of endogenous estrogen in regulation of bone resorption in late postmenopausal women. J Bone Miner Res. 2002; 17(1):172-178.

23. Brixen K, Nielsen HK, Eriksen EF, Charles P, Mosekilde L. Efficacy of wheat germ lectinprecipitated alkaline phosphatase in serum as an estimator of bone mineralization rate: comparison to serum total alkaline phosphatase and serum bone Gla-protein. Calcif Tissue Int. 1989;44(2):93-98.

24. Abdallah IZ, Khattab HA, Sawiress FA, El-Banna RA. Effect of salvia officinalis L. (Sage) herbs on osteoporotic changes in aged non-cycling female rats. Med J Cairo Univ. 2010;78(Suppl 2):1-9.

25. Seibel MJ. Molecular markers of bone turnover biochemical, technical and analytical aspects. Osteoporos Int. 2000;11(Suppl 6):S18-S29.

26. Ducy P, Desbois C, Boyce B, et al. Increase bone formation in osteocalcin deficient mice. Nature. 1996;382(6590):448-452.
27. Nian H, Qin LP, Chen WS, Zhang QY, Zheng HC, Wang Y. Protective effect of steroidal saponins from rhizome of Anemarrhena asphodeloides on ovariectomy-induced bone loss in rats. Acta Pharmacol Sin. 2006;27(6):728-734.

28. Mattix Kramer HJ, Grodstein F, Stampfer MJ, Curhan GC. Menopause and postmenopausal hormone use and risk of incident kidney stones. J Am Soc Nephrol. 2003;14(5):1272-1277.

29. O'Loughin PD, Morris HA. Oestrogen deficiency impairs intestinal calcium absorption in the rat. $J$ Physiol. 1998;511(Pt 1):313-322.

30. Krivosíková Z, Krajcovicová-Kudlácková M, Spustová V, et al. The association between high plasma homocysteine levels and lower bone mineral density in Slovak women: the impact of vegetarian diet. Eur $J$ Nutr. 2010;49(3):147-153.

31. Guillemant J, Taupin P, Le HT, et al. Vitamin D status during puberty in French healthy male adolescents. Osteoporos Int. 1999;10(3): 222-225.

32. Zhang L, Feng X, McDonald JM. The role of calmodulin in the regulation of osteoclastogenesis. Endocrinology. 2003;144(10):4536-4543.

33. Lane NE, Yao W, Kinney JH, Modin G, Balooch M, Wronski TJ. Both $\mathrm{hPTH}(1-34)$ and bFGF increase trabecular bone mass in osteopenic rats but they have different effects on trabecular bone architecture. J Bone Miner Res. 2003;18(12):2105-2115.

34. Orlić I,BoroveckiF, Simić P, VukicevićS. Gene expression profiling in bone tissue of osteoporotic mice. Arh Hig Rada Toksikol. 2007;58(1):3-11.

35. D'Amelio P, Grimaldi A, Di Bella S, et al. Estrogen deficiency increases osteoclastogenesis up-regulating $\mathrm{T}$ cells activity: a key mechanism in osteoporosis. Bone. 2008;43(1):92-100.

36. Şipos RS, Fechete R, Moldovan D, Sus I, Szasz S, Pávai Z. Assessment of femoral bone osteoporosis in rats treated with simvastatin or fenofibrate. Life Sci. 2015;10(1):379-387.

37. Yao W, Farmer R, Cooper R, et al. Simvastatin did not prevent nor restore ovariectomy-induced bone loss in adults rats. J Musculoskelet Neuronal interact. 2006;6(3):277-283.

38. Mundy G, Garrett R, Harris S, et al. Stimulation of bone formation in vitro and in rodents by statins. Science. 1999;286(5446):1946-1949.

39. Wong RW, Rabie AB. Statin collagen grafts used to repair defects in the parietal bone of rabbits. Br J Oral Maxillofac Surg. 2003;41(4): 244-248.

40. Anbinder AI, Balducci I, Rocha RF, Carvalho YR. Influencia da sinvastatina na densidade defects in the parietal [Influence of simvastatin on density defects in the parietal]. RPG Rev Pós-Grad. 2002;9(4):331-336. Portuguese.

41. Lin S, Huang J, Fu Z, et al. The effects of atorvastatin on the prevention of osteoporosis and dyslipidemia in high-fat-fed ovariectomized rats. Calcif Tissue Int. 2015;96(6):541-551.

42. Maeda T, Matsunuma A, Kurahashi I, Yanagawa T, Yoshida H, Horiuchi N. Induction of osteoblast differentiation indices by statins in MC3T3-E1 Cells. J Cell Biochem. 2004;92(3):458-471.

43. Maeda T, Kawane T, Horiuchi N. Statins augment vascular endothelial growth factor expression in osteoblastic cells via inhibition of protein prenylation. Endocrinology. 2003;144(2):681-692.

44. Szulc P, Delmas PD. Biochemical markers of bone turnover: potential use in the investigation and management of postmenopausal osteoporosis. Osteoporos Int. 2008;19(12):1683-1704.

45. Uyar Y, Baytur Y, Inceboz U, Demir BC, Gumuser G, Ozbilgin K. Comparative effects of risedronate, atorvastatin, estrogen and SERMs on bone mass and strength in ovariectomized rats. Maturitas. 2009; 63(3):261-267.

46. Majima T, Komatsu Y, Fukao A, Ninomiya K, Matsumura T, Nakao K. Short-term effects of atorvastatin on bone turnover in male patients with hyper-cholesterolesterolemia. Endocr J. 2007;54(1):145-151.

47. Hughes A, Rogers MJ, Idris AI, Crockett JC. A comparison between the effects of hydrophobic and hydrophilic statins on osteoclast function in vitro and ovariectomy-induced bone loss in vivo. Calcif Tissue Int 2007;81(5):403-413.

48. Hofbauer LC, Brueck CC, Shanahan CM, Schoppet M, Dobnig H. Vascular calcification and osteoporosis from clinical observation towards molecular understanding. Osteoporos Int. 2007;18(3):251-259. 
49. Rattazzi M, Faggin E, Buso R, et al. Atorvastatin Reduces circulating Osteoprogenitor cells and T-cell RANKL Expression in osteoporotic women: Implication for the Bone-Vascular Axis. Cardiovasc Ther. 2016;34(1):13-20.

50. Amara FE, Lachine NA, Hassab A, et al. Statins; a double weapon in treating dyslipidemic osteoporotic menopausal type 2 diabetic women. J Diabetology. 2011;2:3.
51. Tsartsalis AN, Dokos C, Kaiafa GD, et al. Statins, bone formation and osteoporosis: hope or hype? Hormones (Athens). 2012;11(2):126-139.

52. Bauer DC, Mundy GR, Jamal SA, et al. Use of statins and fracture: results of 4 prospective studies and cumulative meta-analysis of observational studies and controlled trials. Arch Intern Med. 2004;164(2):146-152.

\section{Publish your work in this journal}

Drug Design, Development and Therapy is an international, peerreviewed open-access journal that spans the spectrum of drug design and development through to clinical applications. Clinical outcomes, patient safety, and programs for the development and effective, safe, and sustained use of medicines are the features of the journal, which has also been accepted for indexing on PubMed Central. The manuscript management system is completely online and includes a very quick and fair peer-review system, which is all easy to use. Visit http://www.dovepress.com/testimonials.php to read real quotes from published authors.

Submit your manuscript here: http://www.dovepress.com/drug-design-development-and-therapy-journal 